\title{
The Visualization Technology of Sub-compartment Management Procedures Based on WF Technology
}

\author{
Jianjun $\mathrm{Li}^{1}$,Tingdong Yang ${ }^{1}$, Jing Huang ${ }^{1}$, Huaiqing $\mathrm{Zhang}^{2,{ }^{*}}$ and Yongliang $\mathrm{Li}^{2}$ \\ ${ }^{1}$ College of Computer Science and Information Technology, Central South University of Forestry and Technology, Changsha, \\ Hunan, 410004, China \\ ${ }^{2}$ Research Institute of Forest Resource Information Techniques, Chinese Academy of Forest, Beijing, 100091, China \\ ${ }^{*}$ Corresponding author
}

\begin{abstract}
It is hard to program a traditional forest sub-compartment management with a long programming cycle and high energy input and lack of computer technology support, such, this paper presents a visualization technology of the sub-compartment management procedure based on WF. The paper, with the programming theory of forest sub-compartment management and WF technology, abstracted traditional sub-compartment management as management measures modules(TABLE II) and implemented the sub-compartment management procedures of custom design(FIGURE II) and used MOGRE 3D Render Engine to display the results at last. The test data was from the pure forest sub-compartment of Chinese fir in Youxian Huangfengqiao forest farm, Hunan Province. The result shows the 3D scene of sub-compartment and the structure factors before and after the operation(FIGURE $V$ and FIGURE VI), which has the intelligent and visual characteristics. In this way, it can realize the effective detection for management procedure, which sets a foundation for the future intelligent forest management schemes in forest farm level.
\end{abstract}

Keywords-WF; MOGRE; execution method; visualization design; forest sub-compartment management schemes

\section{INTRODUCTION}

Making the sub-compartment management schemes, which are complex and have a lot of considering factors, is the important foothold of making forest management schemes, which is the important step of modern forestry. Therefore, the combination of computer technology and relevant mathematical model to make intelligent forest management plan is the inevitable trend of modern forestry in order to provide decision-making support for business [1-2]. Especially after forest management development to the extent of visualization, forestry developed countries have set up the forest growth simulation system according with national characteristics, which plays a key role in promoting the informatization and standardization of the world forestry [3-5]. The related research about forest management starts late in China. And the forest management plan of statutory nature was defined until the Forestry Law was promulgated in 1985 [6]. The research about the visualization forest management schemes by domestic scholars are less. And most of these schemes analyze the forest spatial attributes of decision-making system with GIS technology. For example, Xiulan Feng et al developed the information management system of collective forest resource based on GIS [7], which realized the forest information resource management of collective forest region in southern China. Duanlv Chen exploited the forest management optimization and subsidiary decision-making system based on GIS [8], which realized the dynamic optimization decision-making system throughout the working plan period. Zhenming Shen et al developed the target tree management assistant decision-making system based on GIS [9], which implemented the scene simulation of pre-and post-stand operations and stand operation assessment. Chuangmu Zheng developed the agroforestry management decision support system based on GIS [10], which offered decision service for the agroforestry management. Huaiqing Zhang et al studied the online decision support system of forestry resources and environment information [11], which provided decision support system based on WEB. With the improvement of the requirements of forestry visualization applications, Yongliang $\mathrm{Li}$ et al developed the visualized simulation of interactive thinning in Chinese Fir plantation based on WF technique [12], which realized preliminarily the management flow of visualization.

Compared with previous research, this study uses the technical means of WF workflow to build the workflow custom activities and the workflow process and the workflow service tracing and the platform between the forest managers and the forest three-dimensional visualization management [7] by the package management scheme and the modularization construction management process and the parameterization of management process technology indexes. And the range of management measures is extended from the aspects of logic and business to detail the design process of management flow. The sub-compartment management scheme is abstracted and encapsulated more scientifically to realize the sub-compartment management scheme of intelligent visualization customization via interactive operation of manager.

\section{STUDY AREA AND DATA SOURCE}

\section{A. Study Area}

This experiment was carried out in the Huangfengqiao state-owned forest farm in Youxian county, Hunan province (113o04'-113o43'E and 27o04'-27o06'N), which is distributed in 13 villages and towns ( 72 villages) and connected with the other forest land. Study sites span an elevation range of 115-1270 m ASL and are mostly middle and low mountain, which slope is general 25o- 350 . The region has a mid-subtropical monsoon wet climate with mean annual 
temperature of $17.8 \mathrm{oC}$ and average sunshine times are 1612 hours. Mean annual precipitation is $1410.8 \mathrm{~mm}$. The forest farm has rich species and outstanding ecological performance with 431 kinds of woody plants, and the tree coverage is up to $86.24 \%$, In this case the selected test sample plot is a sub-compartment with 171 strains of Chinese fir and covers an area of $1200 \mathrm{~m} 2$ with the east-west slope direction and different forest age fir, which is suitable for selective update.

\section{B. Data Source}

The field trips were carried out in the Huangfengqiao forest farm in 2009. A piece of 171 strains of pure Chinese fir forest sub-compartment was selected as a sample plot by the comprehensive understanding of the forest trees growth status and forest resource distribution and sample-plot survey for multiple sub-forest farm, such as Chang Chong, Bai Shi, Guang Huang and so on. The tree's structure factors were measured in the sub-compartment, such as DBH (diameter at breast height), canopy, tree height, clear bole height and other factors. At the same time, the relative coordinates of per tree was measured by using total station. The measured data is shown in TABLE I.

TABLE I. SUB-COMPARTMENT STRUCTURE FACTOR DATA

\begin{tabular}{|c|c|c|c|c|c|c|c|c|}
\hline \multicolumn{9}{|c|}{ Sub-Compartment Structure Factor Data } \\
\hline ID & Tree species & Tree height/m & $\mathrm{DBH} / \mathrm{cm}$ & The forest age level & East-west canopy/m & North-south canopy/m & X coordinate & Y coordinate \\
\hline 1 & Chinese fir & 15.2 & 21 & Mature forest & 3.5 & 4.0 & 4958.775 & 4985.879 \\
\hline 2 & Chinese fir & 14.6 & 19.7 & Mature forest & 3.4 & 3.8 & 4965.626 & 5013.297 \\
\hline 3 & Chinese fir & 11.2 & 13.2 & Half-mature forest & 2.6 & 3.0 & 4960.922 & 4992.785 \\
\hline$\ldots$ & $\ldots$ & $\ldots$ & $\ldots$ & $\ldots$ & $\ldots$ & $\ldots$ & $\ldots$ & $\ldots$ \\
\hline 169 & Chinese fir & 13.1 & 16.7 & Near-mature forest & 3.1 & 3.5 & 4967.609 & 5007.171 \\
\hline 170 & Chinese fir & 13.4 & 17.4 & Near-mature forest & 3.0 & 3.3 & 4959.276 & 4988.038 \\
\hline 171 & Chinese fir & 14.0 & 18.6 & Mature forest & 3.3 & 4.0 & 4963.688 & 5002.008 \\
\hline
\end{tabular}

Combining with 'Chinese fir Binary Stocking List of Hunan Province', sub-compartment stock is calculated by using the data of DBH and tree height and others. And combining with coordinate data, stand structure factors can be calculated, such as uniform angle index and size ratio and other factors $[13,14]$. The structure factors of smallest unit data is contained in TABLE I, which can be used as the test data for management processes.

\section{METHODS}

\section{WF Technology}

WF(Windows Workflow Foundation), published by Microsoft Corp in 2005, is a new generation of workflow framework specific to Windows operating system[15-18], which can quickly generate custom workflow solutions. This framework shares good scalability with two kinds of working forms, the sequential workflow and state workflow[19]. Meanwhile, this framework promotes great autonomy and flexibility of workflow via constructing the hosting layer and the runtime layer and the model layer[20-22].

WF workflow is divided into state machine workflow model and sequential workflow model[15,22]. The state machine workflow model is a workflow model depending on the external event-driven, which includes a series of default states. And the workflow is executed until a default state is triggered. This model is suitable for object-oriented workflow scenarios. Sequential workflow model is a continuous execution module including the branch and loop structure, which can predict the occurrence sequence and be suitable for most workflow application scenarios[23].

For the lack of visualization degree and outstanding of human-computer interaction in the traditional sub-compartment management scheme, measures and factors during management process are encapsulated in the management module in this study. And the workflow model and the state machine model are realized by the custom management processes and module attributes, thus the WF technology is closely integrated with the sub-compartment management processes.

\section{Modular Package Design of Management Process}

Sub-compartment management scheme includes cultivation and cutting, which contains the regeneration, thinning, selective cutting, clear cutting and other management measures. According to forest structure factors (such as $\mathrm{DBH}$, tree height, angle scale, and mingling and so on), sub-compartment management measures are implemented. For example, according to the management principles of 'leaving big trees and cutting small ones', the tree height and DBH can be the main factors as the measurement parameters with different weights and cutting volume, as a result, a reasonable harvesting number of trees can be planed, when thinning is carried out in sub-compartment.

The management process is encapsulated by modular design in this study. According to the corresponding management measures and structural factors and the execution logic of the process, management process is encapsulated into three main directions: management measure module, decision factors module and process execution module. TABLE II shows the three modules.

The management measure module includes harvesting activity and cultivation activity, which contains the thinning, selective cutting, clear cutting, regeneration cutting, pruning and growth and other specific measure module. By setting up the relevant parameters and theoretical model of the management measure module, the sub-compartment management measure is realized via controlling the parameter to guarantee the scientific and standard management. The decision factors module represents forest structure factor reflecting the single plant status of forest trees and the growth status of forest stands, which includes $\mathrm{DBH}$, tree height, size 
ratio, uniform angle index and mingling and so on. In the design process, the decision factors are taken into consideration as the condition factors of the management measure. Mono-factor or multi-factors with different weights is considered to carry out management measure accurately. The process execution module is used to connect the other modules and arrange the sequence of process execution, including data input and output, process pause, sequential execution, parallel execution, looping execution and stand structure contrastive analysis and so on. This module guarantees the flexibility of process design and realizes the dataflow through the three kinds of logic execution sequence and compares the data with stand structure contrastive analysis.

TABLE II. MODULAR PACKAGING OF MANAGEMENT PLAN

\begin{tabular}{|l|l|}
\hline \multicolumn{2}{|c|}{ Encapsulated modules } \\
\hline Package category for business package & Activity \\
\hline \multirow{5}{*}{ Management measure module } & Thinning \\
\cline { 2 - 2 } & Selective cutting \\
\cline { 2 - 2 } & Shelter wood cutting \\
\cline { 2 - 2 } & Clear cutting \\
\cline { 2 - 2 } & Regeneration cutting \\
\cline { 2 - 2 } & Pruning \\
\cline { 2 - 2 } & Growth \\
\hline \multirow{5}{*}{ Decision factors module } & DBH \\
\cline { 2 - 2 } & Tree height \\
\cline { 2 - 2 } & Spatial density \\
\cline { 2 - 2 } & Size ratio \\
\cline { 2 - 2 } & Uniform angle index \\
\cline { 2 - 2 } & Mingling \\
\cline { 2 - 2 } & Health index \\
\hline \multirow{5}{*}{ Process execution module } & Data input \\
\cline { 2 - 2 } & Process pause \\
\cline { 2 - 2 } & Sequential execution \\
\cline { 2 - 2 } & Parallel execution \\
\cline { 2 - 2 } & Looping execution \\
\hline & Data output \\
\cline { 2 - 2 } & Stand structure contrast \\
\hline \multirow{5}{*}{ Compared } & Masure \\
\hline
\end{tabular}

Compared to management measure modules which represents the management process, the operating rules are presented in the form of parameterization on the module attributes. In the management process of the definition by operator, the communication between the modules is realized via the interface and the interaction with the data translated from data tables to the modules. At the same time, in order to ensure the flexibility of the management planning, the management process forms a unified whole, however, the execution time is independent.

\section{E. Visualization Updating Method of Sub-compartment Data}

For the invisible problem of the backstage data, the sub-compartment data of visualization interaction is realized by the flow direction and the module properties.

On the one hand, the data flows with the process flow direction by manager. The sub-compartment data is inputted to flow in the form of table. Then the key field in the data table is recognized and matched and judged in the process module. And the sub-compartment data is updated continually by the algorithm design of the module itself. On the other hand, the property parameters of the module can be calculated by the sub-compartment data. The operator can design the reasonable default parameters to screen data table and update data. FIGURE I gives the detail process.

\begin{tabular}{|c|l|l|l|l|}
\hline $\begin{array}{c}\text { Manage } \\
\text { ment } \\
\text { process }\end{array}$ & $\begin{array}{l}\text { Epdate data } \\
\text { Field matching } \\
\text { and judgment }\end{array}$ & $\begin{array}{l}\text { Sub-co } \\
\text { mpartm } \\
\text { ent data }\end{array}$ & $\begin{array}{l}\text { Property } \\
\text { parameter } \\
\text { calculation }\end{array}$ & $\begin{array}{l}\text { Module } \\
\text { propert } \\
\text { ies }\end{array}$ \\
\hline
\end{tabular}

FIGURE I. UPDATE SUB-COMPARTMENT DATA

\section{RESULTS AND ANALYSIS}

Based on the WF framework and using $\mathrm{C} \#$ language to program the operator-oriented management process editor window and the activity modules, which are dynamic link libraries by writing the inheriting Activity class in nature. And the operation of the custom management processes is completed by overriding the Execute method. Firstly, the data of forest resource inventory is inputted by Data input activity. Secondly, its flow direction and update are displayed in the process with visualization technology. Finally, the data is outputted to the three-dimensional scene by Data output activity. FIGURE II shows how it works.

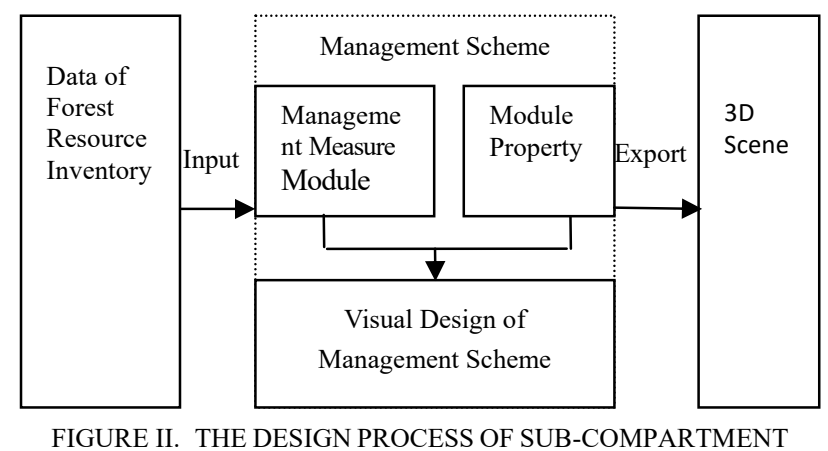
MANAGEMENT

\section{A. Visualization Design Process of Sub-compartment Management Scheme}

Scheme design includes logic design and business design. The logic design is completed in the operating process editing window, which the combination measure module and the decision-making module are defined by the operator. And then the process execution module is connected to complete the scheme of logic design.

Logic design includes sequential logic and parallel logic and looping logic. Sequential logic is often used in the analysis of weight to get the most appropriate screening conditions through the comprehensive consideration of multiple factors. Parallel logic, which executes at least two active axes, is used to obtain the optimal solution by comparing the different axis. Looping logic is used to the tree growth by setting appropriate loop condition and updating data table before satisfying the conditions. Business design is reflected by the attributes of the module. The design of the property is different with the different types of modules, but the relevant modules are defined by setting the key parameters. For example, the growth formula and year are set by the stand growth module and the selective cutting of tree species and density are set by the selective cutting module. And the related model parameters and 
the weight ratio and other factors are set by the decision-making factors module. And the indexes for seeing are set via the stand structure module and the examining of results module and others.

Logic design and business design are stored in the form of XOML file, which provides interactive communication with data in the running process. Specifically, the inventory data is transferred into the management process from the Data Stand module, and is executed according to the process sequence of the XOML file stored. Then the business layer interaction is achieved by the module property parameters, which is recorded inside XOML file. Finally the process pause and the result display are realized by the Terminate Activity module and the See The Effect module. The Management process editing window is shown in FIGURE III.

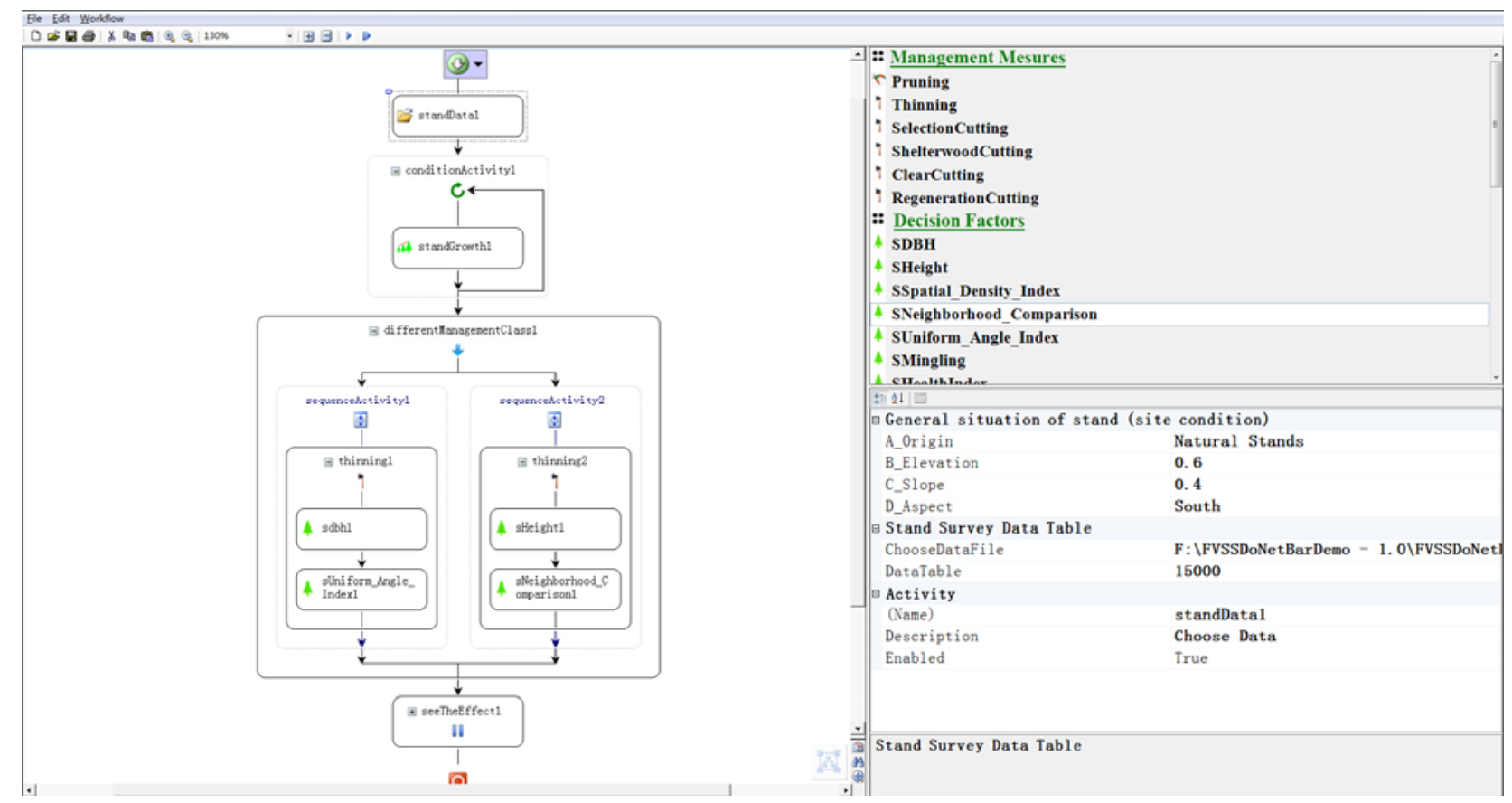

FIGURE III. MANAGEMENT PROCESS EDITING WINDOW

In FIGURE III, the right upper part is the selection area of the sub-compartment management activity module, which encapsulates the different modules for process design. The lower part is the corresponding module of property design area. In this area, different operating parameters are designed according to management ideas to complete the design of the management plan business layer. The left part is the management plan of display area. In this area, the required modules are dragged from the active module area by the operator to build a complete management process. And sub-compartment management scheme is customized through different logic design. Combined these three parts, the operator-oriented management process has great application value.

\section{A. Example of Management Scheme Development}

The selective cutting scheme is designed for the test to make the sub-compartment management scheme through the operator-oriented visualization editing process. The ultimate goal is to display the 3Dscene and compare the main index and before and after management.

Referring to the management plan of the Huang Fengqiao state-owned forest farm forest (2006-2015) to get the concrete modeling process. And the selective cutting intensity is about $25 \% \sim 30 \%$ and the selective cutting cycle is generally 5 to 8 years according to the design principle of 'Leaving big trees and keeping small ones, leaving bad trees and keeping good ones, keeping homogeneous'. After 5 years of growth of Chinese fir plantation, selective cutting with the intensity of $28 \%$ is carried out for this forest in this case. At the same time, the selective cutting of method based on weight and quantization is designed to implement the better and more scientific scheme. FIGURE IV gives the design. 


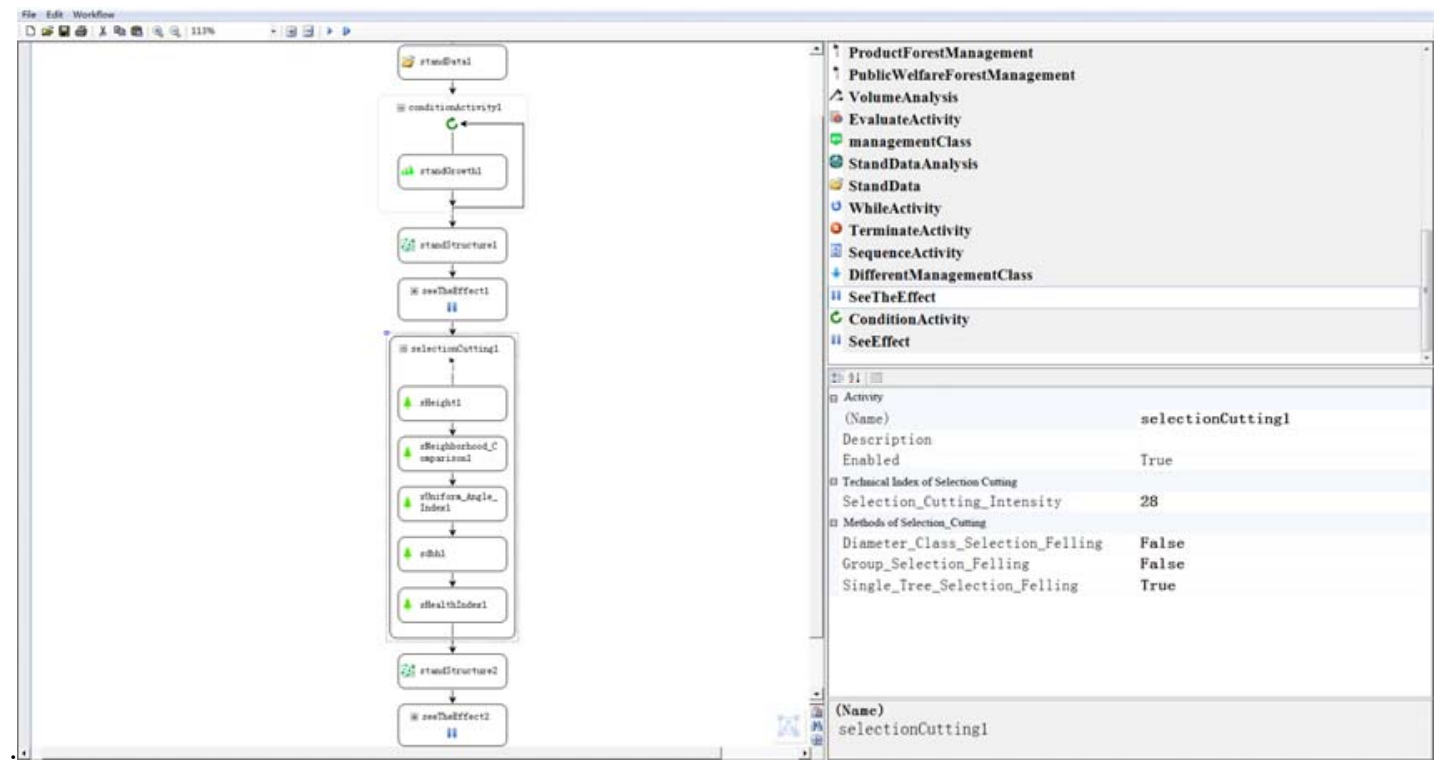

FIGURE IV. MANAGEMENT SCHEME DESIGN OF CHINESE FIR PLANTATION

Firstly, The incoming data is obtained by Stand Data module and the age growth of Chinese fir plantation is implemented by loop module. Until 5 years later, the felling is determined to carry out selective cutting according to the tree height, uniform angle index, $\mathrm{DBH}$, health index and others. And then comparing the effect before and after the operation by the Stand Structure module.

After the start of the custom management process, the design plan will be implemented step by step. The stand structure and $3 \mathrm{D}$ display can be viewed after suspending the first See The Effect module. Then the module is executed. The stand structure and 3D display after the management can be viewed after stopping the second See The Effect module when the process of the selective cutting is end. The main parameters before and after operation is shown in FIGURE $\mathrm{V}$ and FIGURE VI.

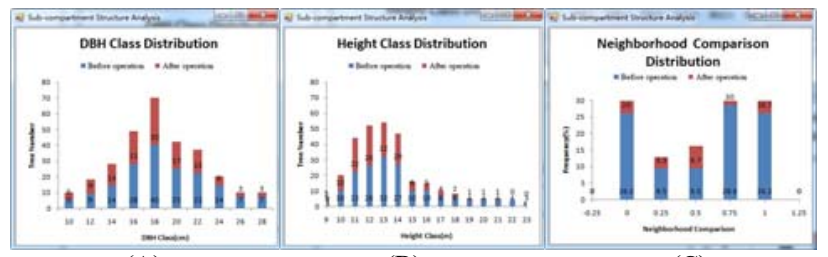

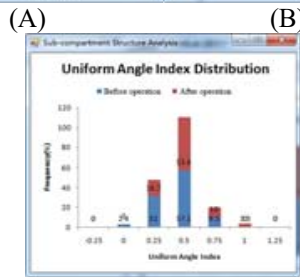

(D)

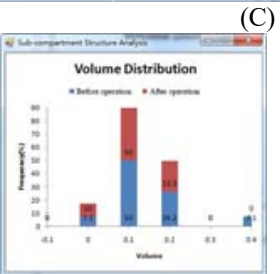

(E)
FIGURE V. COMPARISON OF THE STRUCTURE OF SUB-COMPARTMENT BEFORE AND AFTER OPERATION

(A)breast contrast; (B)height contrast; (C)neighborhood contrast; (D)uniform angle contrast; (E)volume contrast

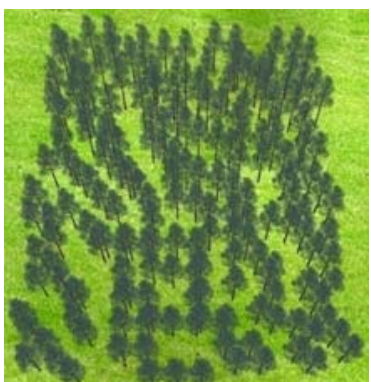

(A)

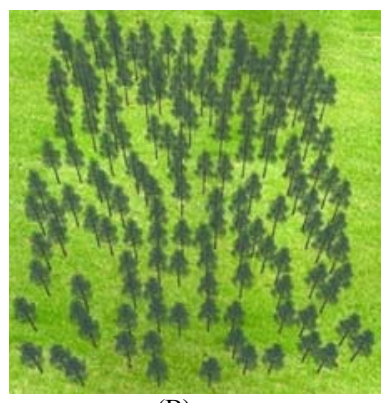

(B)
FIGURE VI. 3D SCENE BEFORE AND AFTER OPERATION

(A)before operation; (B) after operation

In FIGURE V(A), the $10 \mathrm{~cm}$ represents $9 \mathrm{~cm}$ to $10.9 \mathrm{~cm}$ and $12 \mathrm{~cm}$ represents $11 \mathrm{~cm}$ to $12.9 \mathrm{~cm}$ and the rest are similar. In FIGURE V(B), 9m stands for $9.0 \mathrm{~m}$ to 9.9 mand the rest are similar. Red represents the parameters after management and the blue represents the parameters before management. Compared with the parameters, it is obvious that large diameter and tree height of Chinese fir is greatly reduced. And the stand volume downs to 4.9 cubic meters from the 10 cubic meters by calculation, which conforms to the principle of 'Leaving big trees and keeping small ones, keeping homogeneous'.

The sub-compartment situations before and after management are rendered to $3 \mathrm{D}$ scene by using the MOGR engine. The changes before and after management are shown in FIGURE VI(A) and (B), respectively. In FIGURE VI(A), the dense areas are more, which is not conducive to the overall tree growth. Compared with FIGURE VI(A), trees dense areas have been improved in the FIGURE VI(B), which is conducive to the growth of trees and sustainable management.

\section{CONCLUSION}

(1) Designing management plan process based on WF workflow technology has high operability. Operators drag the 
module to design the form of effective and efficient business processes, maximizing the flexibility of program development in the business process editor window. Implementing activities module content by editing the properties with fast and intuitive way of expressing design process, reflects good human-computer interaction.

(2) Designing flexible business processes with diverse business process design approach. Based on WF technology, operators can design sequential logic and parallel logic and looping logic. And complete custom design workflow by freely combining different logic.

(3) To quantify the business activities of planning, so that the development of the management plan is based on a mathematical model of the above. With the set module properties and the external events in preset management processes, on one hand it improves the process logic, on the other hand it makes the process more scientific, meanwhile it improves the accuracy of the management plan, provides a guarantee for the correctness of the design management plan.

(4) As a decision-support system, there still exists much limit in decision factors. Currently only take into account factors such as forest structure $\mathrm{DBH}$, tree height, mingling, uniform angle index and other factors, each consideration is based on the theoretical model, lacking consideration of the actual forest growth process factors such as climate, this is also an important aspect of future research needs.

\section{ACKNOWLEDGEMENT}

Project supported by the National Natural Science Foundation of China (NO.31570627), the Science and Technology Project Program of Hunan Province (No. 2014NK3091), the Graduate Student Science and Technology Innovation Foundation Program of Central South University of Forestry and Technology (No. CX2015B18), the National High Technology Research and Development Program of China( 863 Program) (NO. 2012AA102002), forest resources integration of field data acquisition technology import(948 Project) (2015-4-3).

\section{REFERENCES}

[1] Tyrvainen L, Gustavsson R, Konijnendijk C, et al. Visualization and landscape laboratories in planning, design and management of urban woodlands[J].forest Policy and L, Economics, 2006,8(8):811-823.

[2] Hai L, Huaiqing Z, Hui L. A Review of Visual Simulation of Forest Management[J]. World Forestry Research, 2010, 23(1):21-27.

[3] Tao W. Study on typical patterns and policies of forest management abroad and implications for China[D]. Beijing Forestry University, 2012.

[4] FORSTVEREIN S. Naturnaher waldbau als gesetzlich verankerter standard fur die Waldbewirlschaflung [J]. Schweiz Z Forstwes, 2004,155 (12) : 555-557.

[5] EMIN Z B SEDAT K, HACI A Y. Comparing multipurpose forest management with timber management, incorporating timber, carbon and oxygen values: a case study [J]. Scandinavian J For Res, 2008,23: 105-120.

[6] Jie G, Xuanrui H, Zhongqi X. The managed study of Forest Management Plan[J]. Hebei Journal of Forestry and Orchard Research, 2008,23(1):40-44.

[7] Xiulan F, Tieying S, Jianxin Y et al. Information management system of collective owned forest resource based on GIS[J]. Journal of Beijing Forestry University, 2001,23(3):81-85.
[8] Duanlv C. Forest management Optimization and Subsidiary Decision-making System based on GIS Technology[D]. Central South Forestry College,2002:12.

[9] Zhenming S, Yixiang W, Tianhang W et al. A target tree management assistant decision-making system based on GIS[J]. Journal of Zhejiang A \& F University, 2013,30(5) : 633-639.

[10] Chuangmu Z. Development and Application of Agroforestry Decision Support System Based on GIS[D]. Huazhong Agricultural University, 2005:32.

[11] Huaiqing Z, Hongbo J, Yongfu C. Study on Online Decision Support System of Forestry Resources and Environment Information[J]. Forest Research, 2002,15(6):637-643.

[12] Yongliang L, Hongbo J, Huaiqing Z et al. Visualized Simulation of Interaction Thinning in Chinese Fir Plantation Based on Workflow Technique[J]. Forest Research, 2014,27(3):329-334.

[13] Gangying H, Yanbo H, Hai X. Quantitative Analysis of Forest Spatial Structure[A]. Chinese Society of Forestry. 2005 China Association Annual Conference Proceedings 26 Session (2) [C].Chinese Society of Forestry, 2005:5.

[14] HEGYI F. A simulation model for managing Jack-pine stands[M]//FRIES J. Growdh Models for Tree and Stand Simulation. Stockholm: Royal College of Forest, 1974:74-90.

[15] Yangui W. Analysis and Study of WF Workflow Framework[J]. China CIO News, 2012,(9):128-131.

[16] Xueming W. Research on Visual Simulation Technology of the Process of Chinese Fir Plantation Stand Management[D]. Changsha: Central South University of Forestry \& Technology, 2012.

[17] Liguo Y. The Study and Application of Workflow Technology Based on WF[D]. Wuhan: Wuhan University of Technology, 2008.

[18] Xinxing H. Application of Workflow Management Information System Based on WF[D]. Wuhan:Wuhan University of Science and Technology, 2010.

[19] Yanjun Q, Yaohong Z. Workflow Management System Based WF[J]. Microcomputer Information, 2011,(3):175-177.

[20] Jun H. Research and Application of User-defined Activities Based on Windows Workflow Foundation[D]. Tianjin: TianjinUniversity, 2011:6-7.

[21] Silong Y. Design and application of the Long Transaction Processing Model Based on WF Workflow Engine[D]. University of Chinese Academy of Sciences (College of Engineering \& Information Technology): University of Chinese Academy of Sciences (College of Engineering \& Information Technology), 2015.

[22] Wilvan der Aalst, Kees van Hee. Workflow Management:Models, Methods, and Systems[M].The MIT Press,2002.

[23] Dharma Shukla, Bob Schmidt. Essential Windows Workflow Foundation[M],2006. 